\title{
EPISTEMOLOGIA E METODOLOGIA PARA AS PESQUISAS CRÍTICAS EM ADMINISTRAÇÃO: LEITURAS APROXIMADAS DE HORKHEIMER E ADORNO
}

EPISTEMOLOGY AND METHODOLOGY FOR CRITICAL RESEARCHES IN MANAGEMENT: APPROXIMATE READINGS OF HORKHEIMER AND ADORNO

EPISTEMOLOGÍA Y METODOLOGÍA PARA LAS INVESTIGACIONES CRÍTICAS EN ADMINISTRACIÓN: LECTURAS APROXIMADAS DE HORKHEIMER YADORNO

\section{RESUMO}

Baseado em leituras de Horkheimer e Adorno, autores da chamada primeira geração da Escola de Frankfurt, o texto socializa compreensões sobre ontologia, epistemologia e metodologia crítica visando a contribuir com a prática de pesquisas críticas, de tradição frankfurtiana, no campo da Administração. Parte da discussão ontológica para fundamentar a perspectiva epistemológica frankfurtiana. Apresenta, então, dimensões epistemológicas críticas e propõe três pares categóricos dialéticos para a compreensão da realidade: naturalização versus história, sistema versus práxis social, alienação/dominação versus emancipação. O texto discute aspectos metodológicos e finaliza socializando um exemplo de pesquisa crítica, de tradição frankfurtiana, na Administração.

PALAVRAS-CHAVE Teoria crítica, ontologia, epistemologia, metodologia, pesquisa em administração.

Ana Cristina Batista-dos-Santos anamairton@hotmail.com

Professora do Departamento de Agrotecnologia e Ciências Sociais, Universidade Federal Rural do Semi-Árido - Mossoró - RN, Brasil

Jomária Mata de Lima Alloufa jalloufa@yahoo.com.br

Professora do Programa de Pós-graduação em Administração, Universidade Federal do Rio Grande do Norte - Natal - RN, Brasil

Luciana Holanda Nepomuceno luciananepomuceno@gmail.com

Professora do Departamento de Agrotecnologia e Ciências Sociais, Universidade Federal Rural do Semi-Árido - Mossoró - RN, Brasil

Recebido em 17.12.2009. Aprovado em 09.06.2010

Avaliado pelo sistema double blind review

Editor Científico: Alexandre de Pádua Carrieri

ABSTRACT Based on readings of Horkheimer and Adorno, authors of the so-called first generation of Frankfurt School, the text socializes understandings regarding critical ontology, epistemology and methodology aiming to contribute with the practice of critical research within the Frankfurtian tradition in the management field. The paper sets off with ontological discussion to substantiate the Frankfurtian epistemological perspective. It then introduces critical epistemological dimensions and suggests three dialectic categorical pairs for understanding reality: naturalization versus history, system versus social praxis, alienation/domination versus emancipation. The text discusses methodological issues and concludes socializing an example of critical research within the Frankfurtian tradition in management.

KEYWORDS Critical theory, ontology, epistemology, methodology, management research.

RESUMEN Basado en lecturas de Horkheimer y Adorno, autores de la llamada primera generación de la Escuela de Frankfurt, el texto socializa comprensiones sobre ontología, epistemología y metodología crítica con el objetivo de contribuir a la práctica de investigaciones críticas, de tradición frankfurtiana, en el campo de la Administración. Parte de la discusión ontológica para fundamentar la perspectiva epistemológica frankfurtiana. Presenta, entonces, dimensiones epistemológicas críticas y propone tres pares categóricos dialécticos para la comprensión de la realidad: naturalización contra historia, sistema contra praxis social, alienación/dominación contra emancipación. El texto discute aspectos metodológicos y finaliza socializando un ejemplo de investigación crítica, de tradición frankfurtiana, en la Administración.

PALABRAS CLAVE Teoría crítica, ontología, epistemología, metodología, investigación en administración. 


\section{INTRODUÇÃO}

Este trabalho trata da crítica no campo da Administração, crítica tomada no sentido vinculado aos trabalhos da Escola de Frankfurt. Inspirado em leituras aproximadas de Adorno e Horkheimer, este texto compreende que a crítica, em sentido frankfurtiano, é aquela que põe em suspenso qualquer juízo sobre o mundo, para sua prévia interrogação, e é própria de um pensamento que coloca a si mesmo em julgamento, investindo na autorreflexividade, porque crê que "a liberdade na sociedade é inseparável do pensamento esclarecedor" (ADORNO; HORKHEIMER, 1985, p. 1).

Os frankfurtianos convergiam para o interesse comum de uma "compreensão totalizante e dialética, capaz de fazer emergir as contradições da sociedade capitalista" (FARIA, 2004, p. 26). Considerada pejorativamente como radical, a teoria crítica (doravante TC) é de fato radical no sentido de que sempre vai à raiz dos fenômenos. Sua pertinência ao âmbito da Administração se dá pela contribuição em desvelar o mundo do poder, em suas instâncias obscuras e manifestas, e as formas sempre atualizáveis de controle nas organizações capitalistas (FARIA, 2003, 2004, 2007).

A possibilidade de uma teoria e práxis críticas, de inspiração frankfurtiana, no âmbito da pesquisa brasileira em Administração, é defendida e empreendida por pesquisadores como Faria (2004), Paula (2008) e Tenório (2004), dentre outros. Entretanto, embora o debate teórico sobre a crítica na Administração esteja em crescimento no Brasil, a discussão metodológica, e a ontológica e epistemológica que lhe antecedem, não vêm sendo realizadas com a mesma intensidade.

Assim, este trabalho tem o objetivo de socializar compreensões sobre aspectos ontológicos, epistemológicos e metodológicos críticos visando a contribuir com o avanço das discussões e das práticas de pesquisas críticas, de tradição frankfurtiana, na Administração.

$\mathrm{Na}$ sequência, a segunda parte aborda os temas da ontologia e epistemologia críticas centrando suas argumentações em leituras aproximadas de Adorno e Horkheimer, autores da primeira geração da Escola de Frankfurt (FARIA, 2004; FREITAG, 1986; MATOS, 1993; SLATER, 1978). A terceira parte sugere contornos metodológicos para pesquisas críticas em Administração e exemplifica socializando informações sobre uma experiência de pesquisa com metodologia crítica. As considerações finais são expostas na última parte.

\section{DA ONTOLOGIA E EPISTEMOLOGIA CRÍTICAS}

\author{
Para Assoun (1991, p. 19), o termo "Escola de Frankfurt" \\ é uma
}

[...] etiqueta que serve para marcar um acontecimento (a criação do Instituto), um projeto científico (intitulado "filosofia social"), uma atitude (batizada de "teoria crítica"), enfim uma corrente ou movimentação teórica ao mesmo tempo contínua e diversa (constituída por individualidades pensantes).

Portanto, o que se costuma chamar de Escola de Frankfurt se traduz em uma riqueza originária da pluralidade de intelectuais autônomos. A singularidade dos frankfurtianos se expressou exemplarmente na diversidade de temas de pesquisa privilegiados, onde a variedade é uma de suas marcas. Mas, é nesta dinamicidade intelectual que envolve singularidade e pluralidade, que tal escola legou contribuições, especialmente ao nível dos debates ontológico e epistemológico, com consequências metodológicas. Este trabalho entende que intenções de pesquisa críticas, em sentido frankfurtiano, devem se pautar a partir das bases ontológicas e epistemológicas defendidas pelos frankfurtianos, as quais foram lançadas pelos trabalhos da primeira geração, especialmente os produzidos nos idos dos anos 1930 e 1940 (MUNOZ, 2000; SLATER, 1978).

Este trabalho privilegia concepções aproximadas de Horkheimer e Adorno. Matos (1993) afirma que Horkheimer e Adorno já se conheciam desde a década de 1920, porém, é durante a década de 1930, especialmente a partir do exílio nos Estados Unidos, que os dois se aproximam e passam a trabalhar juntos. Muñoz (2000) argumenta que a parceria de Adorno e Horkheimer foi fundamental para a proposição e consolidação do paradigma crítico na sociedade contemporânea: "Horkheimer e Adorno - Adorno e Horkheimer - fundam e assentam a nova perspectiva teórica, sem a qual haveria sido difícil ter uma visão crítica do sucedido ao longo do Século das Massas" (MUÑOZ, 2000, p. 29). A primeira obra conjunta e de grande repercussão foi A dialética do esclarecimento, escrita em 1947, sobre cujo processo de construção em parceria os autores afirmam:

Ao reeditá-lo [1969], decorridos mais de vinte anos, não somos movidos apenas pelas múltiplas solicitações, mas pela crença de que não poucos dos pensamentos ainda são atuais e têm determinado em larga medida nossos esforços teóricos ulteriores. [...] Juntos ditamos largos trechos, 
e a tensão dos dois temperamentos intelectuais que se juntaram na "Dialética" é seu elemento vital. (ADORNO; HORKHEIMER, 1985, p. 1)

Dos primeiros escritos de Adorno e Horkheimer, dois deles tocam diretamente no aparentemente paradoxal tema da "ontologia frankfurtiana": do primeiro, A ideia de história natural (2004), e do segundo, Materialismo e metafísica (1990). Ambos combatem em seus textos uma ontologia prisioneira dos sentidos do idealismo kantiano ou do essencialismo de raiz fenomenológica.

Horkheimer (1990) defende em Materialismo e metafísica, escrito em 1933, a ideia do que se poderia chamar de uma "ontologia materialista", porque distinta da metafísica ou de um idealismo, com implicações epistemológicas claras: "O materialismo tenta uma explicação através da compreensão histórica" (HORKHEIMER, 1990, p. 41).

Semelhantemente, na conferência intitulada A ideia de história natural, proferida em 1932, Adorno (2004) intervém na chamada discussão frankfurtiana que girava em torno da questão ontológica. Nessa época, havia o debate no contexto da fenomenologia pós-husserliana, que tentava uma correção da dualidade corrente entre natureza e história. Adorno (2004) via esse giro fenomenológico como uma tentativa de dissolver e dinamizar as concepções até então polarizadas em torno das relações entre ontologia e história. Porém, em sua visão, a "nova" fenomenologia, ancorada no conceito de historicidade, permanecia refém de uma perspectiva equivocada em relação à história enquanto dimensão ontológica, pois mesmo a tendo admitido, todavia a vinculou a uma estrutura (histórica) geral e global do ser, e assim, consequentemente, não soube lidar com a materialidade da faticidade que se apresenta no devir histórico. Dessa reflexão sobre o giro fenomenológico, Adorno (2004) propõe o conceito dialético de história natural:

É mérito da posição ontológica [fenomenológica póshusserliana] haver elaborado internamente o insuperável entrelaçamento entre os elementos da natureza e da história. Por outro lado, é necessário purificar esse projeto da representação de uma totalidade abarcadora. [...] Se a questão da relação entre natureza e história deve ser colocada seriamente, então ela apenas oferece uma perspectiva, como resposta, quando consegue compreender o ser histórico como um ser natural em sua determinação histórica extrema, lá onde, ele mesmo, é maximamente histórico, ou quando consegue compreender a natureza, como ser histórico, lá onde, em aparência, ela persiste em si mesma, no mais profundo de si, como natureza. Já não se trata mais de conceber o fato da história em geral, sob a categoria de historicidade, como um fato natural, e sim de retransformar, em sentido inverso, a disponibilidade dos acontecimentos intra-históricos em uma disposição de acontecimentos naturais. Não é procurar um ser puro, subjacente ao ser histórico, ou que se encontraria nele, e sim compreender o próprio ser histórico como ontológico, isto é, como ser natural. Transformar assim, em sentido inverso, a história concreta em natureza dialética é a tarefa da ontológica mudança de orientação da filosofia da história: a ideia da história natural. (ADORNO, 2004, p. 6)

Considerando tais perspectivas ontológicas, pode-se compreender o que se poderia chamar de epistemologia frankfurtiana.

Quanto aos fundamentos epistemológicos, a TC opõese ao que Horkheimer (1980) nomeia de teoria tradicional (doravante TT), tensão que é apresentada por Adorno (1980) nos termos: lógica dialética versus lógica formal. A TT é aquela que se apresenta como um processo de pensamento de operação linear, buscando uma lógica causal dos acontecimentos que seja aplicável aos da mesma natureza de modo isomórfico. Situar-se epistemologicamente no território da TC é posicionar-se contra o positivismo empirista e o positivismo lógico popperiano (ADORNO, 1980, 1986), o que implica a rejeição dos métodos indutivistas e dedutivistas de compreensão da realidade. A TC vê a dialética como a lógica constituinte da realidade e como método apropriado para a construção de conhecimento sobre essa realidade.

A TC opõe-se ao pensamento da não contradição, construído sob a lógica da identidade ou da "racionalidade do sempre igual" (ADORNO, 1995b, p. 203). Ao contrário, a TC trabalha com a lógica da negatividade da dialética. Adorno (1980) rebate o ataque positivista de que a dialética teria um cunho meramente especulativo, como se o dialético fosse aquele que pensa futilmente sem compromisso, sem autocrítica e sem confrontação com as coisas. Responde lembrando que a dialética não é um método independente do seu objeto. A crítica dialética tem um compromisso com qualquer objeto e opera mediante o desvelamento de suas contradições, estas compreendidas em face da totalidade, e não de maneira segmentada.

A visão de totalidade implica a consideração da dinâmica e da complexidade da vida social, tratando-a a partir de uma compreensão histórica (HORKHEIMER, 1990). Rejeita a segmentação simplificadora de um pensamento que considera a realidade social como constituída de par- 
tes estanques e que opera cisões apriorísticas entre sujeito e objeto, entre teoria e práxis (ADORNO, 1995b), ou entre conceito e existência (HORKHEIMER, 1990). Pela noção de totalidade, compreende-se que sujeito e objeto existem tão somente em situação de relação, donde ao próprio conhecimento é negada toda possibilidade de autonomia, tendo em vista que este se refere ao "pensar de determinados homens numa determinada época" (HORKHEIMER, 1990, p. 47). Essa é a totalidade a ser considerada, porém, não sob a lógica do pensamento identitário, pois, como adverte Adorno (1980, p. 217): "A totalidade não constitui uma categoria afirmativa, mas sim crítica".

A parte é constituída do todo e formadora do todo, que não é sem suas partes, as quais, contudo, possuem um movimento próprio articulado na totalidade, sem a ela se reduzir. Assim, na visão de Adorno (1980), a compreensão dos eventos fáticos é conducente à totalidade, sem que esta seja, em si, um fato; ideia que, para Horkheimer (1990), constitui um dos fundamentos do processo dialético, o qual entende se caracterizar pela mudança recíproca e contínua dos elementos dentro do próprio processo de tal forma que não podem ser definitivamente distinguidos entre si.

Só considerando a dinâmica histórica é que se tornam possíveis a identificação e a compreensão dos antagonismos reais que, segundo Adorno (1980), apenas a lógica dialética é capaz de apreender, ao contrário da lógica formal, que, ao insistir na lógica da identidade, desconsidera que o movimento e o desenvolvimento dos fenômenos residem nas contradições que os constituem. Portanto, no centro do pensamento crítico, autorreflexivo, reside a negatividade, que requer pensar o dito e o vivido como contendo em si mesmos contradições.

\section{Os pares categóricos dialéticos}

Tomar a dialética como fulcro de uma práxis de pesquisa crítica implica um fazer metodológico que permita "captar" a tensão dialética inerente aos fenômenos. Este trabalho entende que isso é possível na medida em que se conheça e se paute a pesquisa crítica, de inspiração frankfurtiana, a partir das categorias epistemológicas da TC, em sua tensão dialética. Este texto, fundamentado em leituras aproximadas de Horkheimer e Adorno, propõe três pares categóricos dialéticos. De Horkheimer (1980), toma como referência o texto Teoria tradicional e teoria crítica (TTTC), escrito em 1937, considerado uma espécie de manifesto da Escola de Frankfurt (MATOS, 1993; SLATER, 1978). De Adorno (1980), debruça-se no texto Introdução à controvérsia sobre o positivismo na sociedade alemã (ICPSA), obra publicada em 1974, cinco anos após sua morte, em que Adorno retoma e ratifica o antagonismo já alertado por Horkheimer, no "manifesto", entre a lógica positivista (formal) e a lógica crítica (dialética), apontando e aprofundando a distância teórica que separa epistêmica e ontologicamente a dialética do método positivista (GANEM, 2009). Dos autores em conjunto, toma-se o texto A dialética do esclarecimento (DE), escrito em 1947, no qual Horkheimer e Adorno (1985) empreendem uma reflexão conjunta sobre o desenrolar histórico da proposta da razão iluminista, e o fazem pautados em categorias críticas que se desvelam no texto.

Por meio de uma atenção às categorias epistemológicas que fundamentam a perspectiva dos frankfurtianos de primeira geração, pode-se compreender como presentes, nos textos selecionados, pelo menos três pares dialéticos: 1) naturalização-história (Quadro 1), 2) sistema-práxis social (Quadro 2), 3) alienação/dominação-emancipação (Quadro 3).

Para facilitar a identificação da relação dos argumentos aqui propostos com as ideias dos autores, os excertos extraídos das obras foram assim codificados: no Quadro 1: H1 e H2 (trechos de Horkheimer); Al e A2 (trechos de Adorno); AH1 e AH2 (trechos conjuntos); no Quadro 2: H3 e H4 (trechos de Horkheimer); A3 e A4 (trechos de Adorno); AH3 e AH4 (trechos conjuntos); no Quadro 3: H5 e H6 (trechos de Horkheimer); A5 e A6 (trechos de Adorno); AH5 e AH6 (trechos conjuntos). Esses códigos acompanham a argumentação que se empreende a seguir.

O Quadro 1 exemplifica, com excertos das obras selecionadas, o primeiro par dialético: naturalização versus história.

$\mathrm{Na}$ perspectiva da TT, no ato de conhecer, considerase a seqüência dos acontecimentos como oriunda do determinismo natural, logo, independente da interferência humana. Horkheimer e Adorno vêem nesta perspectiva um movimento de coisificação dos fenômenos sociais (A1), em que os mesmos são tratados como coisas dadas, portanto, a-históricas (H1). Contra isso, Horkheimer adverte sobre o caráter histórico tanto do sujeito quanto do objeto do conhecimento (H2). Pela perspectiva crítica, rejeita-se o pensar que permanece na superfície dos dados, pela subordinação obediente da razão ao imediatamente dado. Em ICPSA, Adorno parte das idéias de Horkheimer e avança para explicar que se deve sempre considerar a constituição histórica dos fenômenos sociais se realmente almeja-se compreendê-los, donde destaca as dimensões objetivas (momentos econômicos, históricos) e subjetivas (momentos psicológicos), sugerindo um constante movimento pendular entre objetividade e subjetividade 
(A2), que capte o entrelaçamento entre o individual e o social. $\mathrm{Na} D E$, os autores desvelam a dimensão política e contraemancipatória contida nos processos de naturalização dos fenômenos sociais (AH1) e ratificam o caráter histórico de sua própria teoria (AH2). Assim, desde o ponto de vista do pensar e fazer críticos, busca-se ver, no dado particular, sua inscrição material e histórica. As relações temporal e espacialmente circunstanciadas são o foco de interesse, bem como os processos sociais em suas dimensões multifacetadas.

O Quadro 2 apresenta trechos do par dialético: sistema versus práxis social.

Em TTTC, Horkheimer denuncia a postura sistêmica da TT que toma a realidade social como formada por elementos, organizados numa lógica harmônica que elimina a contradição (H3), e alerta que essa postura só é possível porque a TT opera mediante uma lógica de retirada dos fenômenos sociais de seu contexto "natural", que é histórico: a práxis social (H4). Assim é que, para Adorno, essa postura harmonizadora mecânica constitui a colocação de um véu por parte da ciência normal, que escamoteia os antagonismos inscritos em sua base material que é a práxis (A3). Em sua réplica a Popper sobre a lógica das ciências sociais, Adorno (1986, p. 21) afirma que "as teorias sistêmicas positivistas procuram meramente sintetizar de forma não contraditória suas afirmações sobre o real, situando-as em um contíguo lógico". A exigência do pensamento positivista é que todos os elementos estejam ligados de modo direto e não contraditório, de forma que todas as proposições referentes a um determinado campo possam ser derivadas de algumas poucas. Dessa maneira a totalidade é transformada em um sistema unificado e matemático de signos, contradição que Horkheimer já havia destacado na TTTC.

A TC, ao contrário, apresenta como característica o fato de que não objetiva nenhuma visão definitiva da totalidade social, e toma a totalidade da práxis social como dimensão central para a crítica dialética, considerando seus antagonismos reais que emergem no devir histórico; em oposição à faticidade redutora da

Quadro 1 - Par categórico dialético da TC: naturalização versus história

\section{PERSPECTIVA TRADICIONAL}

(NATURALIZAÇÃO)

(H1) A gênese social dos problemas, as situações reais nas quais a ciência é empregada e os fins perseguidos em sua aplicação são elementos exteriores ao homem e à própria ciência. Tratase de uma coisa dada, cujo único problema é a constatação e previsão segundo as leis da probabilidade. 0 que é dado depende apenas da natureza. (TTC, p. 155).

(A1) No interior da sociedade coisificada, nada tem chance de sobreviver que por sua vez não seja coisificado. [...] 0 positivismo encara a sociologia como uma ciência entre as outras, e, desde Comte, considera os consagrados métodos da ciência mais antiga, sobretudo a da natureza, como aplicáveis à sociologia. É aqui que está contido o engano propriamente dito. [...] 0 positivismo trata sem mais a sociedade, como se fosse um objeto a ser determinado a partir do exterior. Tal substituição de sociedade como sujeito por sociedade como objeto constitui a consciência coisificada da sociologia. (ICPSA, p. 213-233)

(AH1) Os processos naturais recorrentes e eternamente iguais são inculcados (por poucos) como ritmo do trabalho nos homens submetidos. A repetição da natureza, que é o seu significado, acaba sempre por se mostrar como a permanência, por eles representada, da coerção social. (DE, p. 16)

\section{PERSPECTIVA CRÍTICA FRANKFURTIANA} (HISTÓRIA)

(H2) Os fatos que os sentidos nos fornecem são pré-formados de modo duplo: pelo caráter histórico do objeto percebido e pelo caráter histórico do órgão perceptivo (TTC, p. 125).

(A2) Horkheimer foi o primeiro a assinalar que fatos sociais não são previsíveis da mesma maneira que o são fatos das ciências naturais no interior dos seus contínuos mais ou menos homogêneos. Entre a objetiva conformidade às leis da sociedade, conta-se seu caráter contraditório. [...] Desprovida de todos os momentos econômicos, históricos, sociais e psicológicos, nada mais faria a sociologia do que rodear temerosamente qualquer fenômeno social. (ICPSA, p. 240-249)

(AH2) Não nos agarramos sem modificações a tudo o que está dito no livro (Dialética do Esclarecimento). Isso seria incompatível com uma teoria que atribui à verdade um núcleo temporal. (DE, p. 1) 
história, e à lógica de funcionamento sistêmico contido no esquema dedutivo positivista (A4), que trabalha na perspectiva de uma ciência unitária (AH3). Na DE, Adorno e Horkheimer salientam a importância da teoria para uma práxis emancipatória, ao imputarem àquela a tarefa de combater a falsa consciência do pensamento no seio social (AH4).

O terceiro par dialético - alienação/dominação versus emancipação - é exemplificado com os trechos do Quadro 3.

Na crítica à tradição positivista de pensar a sociedade sistemicamente, amparada por uma lógica unitária e estática de ciência, tanto Adorno quanto Horkheimer desvelam os conteúdos de alienação e dominação contidos nesse tipo de pensamento, e não se furtam de tentar compreender sua emergência no contexto do trabalho inscrito na sociedade capitalista moderna (H5, A5, A6). Eles exemplificam o exercício dialético de pensar a relação entre o particular e a totalidade, e, assim, desvelam os antagonismos reais da relação homem-natureza-sociedade, presente na lógica da unidade sistemática da ciência, que parece corresponder à unidade da coletividade manipulada que implica a alienação dos indivíduos (AH5). Assim, defendem que a TC reclama um comportamento crítico que tem em vista a emancipação. Emancipação essa entendida como conscientização que se organiza como reflexão racional pela qual o que aparenta ser a ordem natural e essencial, na sociedade cultural, é decifrado como ordem socialmente determinada em condições dadas de produção real e efetiva da sociedade. Eles defendem o comportamento orientado para a emancipação e destacam a importância do trabalho teórico nessa missão, alertando, contudo, que a contribuição da ciência inclui dispensar o pragmatismo próprio ao positivismo (H6), e que o pensamento crítico deve permanecer atuante mesmo diante de uma

Quadro 2 - Par categórico dialético da TC: sistema versus práxis social

\section{PERSPECTIVA TRADICIONAL}

(SISTEMA)

(H3) Uma exigência fundamental, que todo sistema teórico tem que satisfazer, consiste em estarem todas as partes conectadas ininterruptamente e livres de contradição. (ПTC, p. 118)

(A3) A ciência [formal] ajuda a tecer um véu. Sua tendência harmonizadora permite, graças ao seu metódico tratamento mecânico, o desaparecimento dos antagonismos da realidade efetiva; repousa no método classificatório, sem qualquer intencionalidade dos que dele se utilizam. Reduz a um mesmo conceito coisas essencialmente irredutíveis e contraditórias, por meio da escolha do aparato conceitual e a serviço de sua unanimidade. [...] A unificação da ciência desloca a contraditoriedade de seu objeto. [...] 0 método lógico da redução a elementos a partir dos quais algo social se constrói, elimina virtualmente contradições objetivas (ICPSA, p. 220-241)

(AH3) 0 esclarecimento só reconhece como ser e acontecer 0 que se deixa captar pela unidade. Seu ideal é o sistema do qual se pode deduzir toda e cada coisa. [...] Embora as diferentes escolas (racionalista e empirista) interpretassem de maneira diferente os axiomas, a estrutura da ciência unitária era sempre a mesma. [...] A multiplicidade das figuras se reduz à posição e à ordem; a história ao fato; as coisas à matéria. [...] A lógica formal era a grande escola da unificação. Ela oferecia aos esclarecedores o esquema da calculabilidade do mundo. (DE, p. 9)

\section{PERSPECTIVA CRÍTICA FRANKFURTIANA} (PRÁXIS SOCIAL)

(H4) É preciso passar para uma concepção que elimine a parcialidade que resulta necessariamente do fato de retirar os processos parciais da totalidade da práxis social (TTC, p. 124).

(A4) Não apenas o objeto do conhecimento é mediatizado pelo sujeito, [...] mas também inversamente: 0 sujeito incide como momento na objetividade a ser por ele conhecida, o processo social. [...] A contradição dialética exprime os antagonismos reais que não ficam visíveis no interior do sistema lógico-cientificista de pensamento. 0 sistema, conforme o modelo do lógico-dedutivo, constitui algo desejável, algo positivo para os positivistas; já para os dialéticos, tanto real como filosoficamente, constitui o cerne a ser criticado. (ICPSA, p. 220-227)

(AH4) Mas uma verdadeira práxis revolucionária depende da intransigência da teoria em face da inconsciência com que a sociedade deixa que o pensamento se enrijeça. Não são as condições materiais da satisfação nem a técnica deixada à solta enquanto tal, que a colocam em questão. [...] A culpa é da ofuscação em que está mergulhada a sociedade. (DE, p. 28) 
realidade que se apresenta com poucas possibilidades emancipatórias (AH6). Eles consideram que mesmo a sociologia empírica que criticam com veemência deveria, em lugar de se opor à lógica dialética, ocupar-se com a análise do movimento de produção da dominação e alienação (A6). Trata-se, então, de uma atitude crítica que envolve a compreensão da práxis social e o desvelar das situações de dominação tendo em vista não a reprodução social, mas a sua transformação por meio da crítica ideológica emancipatória. Como eles propunham: é preciso ser um pessimista teórico, mas, sempre, um otimista prático.

\section{METODOLOGIA CRÍTICA: SEUS PRINCÍPIOS E UMA BREVE EXEMPLIFICAÇÃO}

Este trabalho considera o campo da Administração como propício à prática de pesquisas críticas, e toma o termo "campo" no sentido que lhe dá Bourdieu (2003), isto é, como um espaço em que são agenciadas as relações materiais de forças. Sendo o campo da Administração, especialmente o da Administração de Empresas, o espaço por excelência de emergência da relação dialética entre capital e trabalho, esse campo se apresenta como apropriado ao estudo e compreensão das contradições da sociedade capitalista, intenção privilegiada pelos frankfurtianos. Os objetos da Administração, uma vez problematizados numa perspectiva crítica, isto é, partindo da tensão de base constituinte das organizações capitalistas, podem ser pesquisados por meio de um método igualmente crítico porque pautado nas categorias epistemológicas críticas, as quais norteiam o trabalho em todas as suas fases.

Convergentemente aos aspectos epistemológicos, a operacionalização de uma pesquisa crítica se dá numa perspectiva não linear e se pauta numa premissa: a lógica dialética. Além disso, deve-se levar em conta: (i) a orientação de todas as fases da pesquisa pelo quadro de referência da TC, utilizando-se dimensões categóricas críticas como uma lente crítica; (ii) que a realidade é sempre maior do que aquilo que o pesquisador pode acessar e compreender; (iii) que todas as fases da pesquisa estão inter-relacionadas, não podendo ser tratadas de maneira isolada e fragmentária; (iv) que as técnicas metodológicas a serem escolhidas dependem da natureza do objeto.

Especialmente no tocante ao quarto ponto, é importante destacar que não há uma metodologia crítica padrão e homogênea a ser utilizada de maneira indiscriminada e, portanto, acrítica, em pesquisas que se propõem críticas.

Quadro 3 - Par categórico dialético da TC: dominação/alienação versus emancipação

PERSPECTIVA TRADICIONAL

(DOMINAÇÃO/ALIENAÇÃO)

(H5) A aparente autonomia nos processos de trabalho, cujo decorrer se pensa provir de uma essência interior ao seu objeto, corresponde à ilusão da liberdade dos sujeitos econômicos na sociedade burguesa. Mesmo nos cálculos mais complicados, eles são expoentes do mecanismo social invisível, embora creiam agir segundo suas decisões individuais. (ITC, p. 123)

(A5) Na configuração pós-liberal da sociedade, sua unidade sistemática vai se amalgamar, como totalidade, com a repressão. (ICPSA, p. 228)

(AH5) 0 que os homens querem aprender da natureza é como empregá-la para dominar completamente a ela e aos homens. [...] A unidade da coletividade manipulada consiste na negação de cada indivíduo. (DE, p. 7-12)

\section{PERSPECTIVA CRÍTICA FRANKFURTIANA} (EMANCIPAÇÃO)

(H6) Um comportamento que esteja orientado para a emancipação, que tenha por meta a transformação do todo, pode servirse sem dúvida do trabalho teórico, tal como ocorre dentro da ordem da realidade existente. Contudo ele dispensa o caráter pragmático que advém do pensamento tradicional (TTC, p. 131)

(A6) Uma tarefa relevante da sociologia empírica seria analisar os elos intermediários, demonstrar em detalhe como a adaptação às relações capitalistas de produção transformadas se apodera daqueles cujos interesses objetivos à la longue (com o tempo) se contrapõem àquela adaptação.

(AH6) 0 pensamento crítico, que não se detém nem mesmo diante do progresso, exige hoje que se tome partido pelos últimos resíduos de liberdade, pelas tendências ainda existentes a uma humanidade real, ainda que pareçam impotentes em face da grande marcha da história. (DE, p. 2) 
Este trabalho considera infrutífero um posicionamento metodológico não circunstanciado, que não leva em conta nem a natureza do objeto de estudo nem as possibilidades de acesso ao real, conforme Faria (2007) alerta a partir de suas experiências de pesquisas críticas, com fundamentos frankfurtianos no campo da Administração:

\begin{abstract}
Método é um processo e não um instrumento. [...] Instrumentos de coleta de dados são definidos pelo objeto de pesquisa e circunscritos ao campo empírico e não aprioristicamente pelo sujeito, independentemente do objeto e campo. A primazia é do real. (FARIA, 2007, p. 14).
\end{abstract}

Adorno (1980), em sua crítica ao positivismo popperiano, adverte quanto ao risco de um cientificismo nas ciências sociais em que um aprisionamento ao aparato técnico copiado das ciências naturais pode redundar em um distanciamento do que realmente se quer ou se deveria investigar. Ele adverte, então, quanto aos riscos de um reducionismo metodológico, incentivando um posicionamento consciente dos pesquisadores em suas escolhas metodológicas.

\section{Natureza da pesquisa}

Numa pesquisa crítica, é imprescindível a clareza quanto à natureza da pesquisa e, portanto, quanto à abordagem que a orienta. Todavia, a pesquisa crítica mantém-se aberta quanto às possibilidades técnicas para uma aproximação e compreensão mais apropriadas do real. Este trabalho defende que as pesquisas críticas são essencialmente de natureza qualitativa, sendo a perspectiva orientadora.

Por pesquisa de natureza qualitativa, entende-se "uma atividade [historicamente] situada que coloca o pesquisador no mundo, consistindo num campo de práticas materiais e interpretativas que tornam o mundo visível" (DENZIN; LINCOLN, 2000, p. 3), levando-se sempre em conta, numa perspectiva crítica, o sentido que o Outro, enquanto sujeito pesquisado, dá às coisas, e um diálogo dialético desse sentido com a totalidade da práxis social. A pesquisa qualitativa crítica mantém o foco nos processos de significado visando à compreensão de indivíduos, grupos, organizações e a sociedade. Os dados qualitativos são sempre gerados in vivo, perto do ponto de origem, com uma figurativa colocação de marcos, por parte do pesquisador, para delimitar um domínio temporal e espacial do mundo social que ele investiga (VAN MAANEN, 1983), porém sempre considerando a inscrição dos fenômenos que investiga na totalidade da práxis social (ADORNO, 1980).

\section{Técnicas de pesquisa}

Sendo de natureza qualitativa, a técnica de pesquisa privilegiada nas pesquisas críticas é a entrevista, pois oferece a oportunidade de coletar informações por meio da fala dos atores sociais e possibilita entender o que e como as pessoas pensam e sentem acerca do assunto pesquisado. Esse processo de interação com o Outro possibilita tomálo como sujeito particular, não padronizável. A pesquisa crítica considera a relevância das narrativas que os sujeitos fazem das suas práxis como espaço de emergência do seu processo de construção de sentidos em relação dialética com a totalidade.

Um trabalho de campo crítico visa a um contato do pesquisador com o mundo vivido dos sujeitos. Com as entrevistas, busca-se a rememoração do cotidiano, o agir dos sujeitos, sua práxis. Kramer (2001) argumenta que as entrevistas correspondem a espaços de produção de narrativas que se abrem como textos passíveis de compreensão, uma vez que originados na fala individual, que é "reveladora de condições estruturais, de sistemas de valores, normas e símbolos e ao mesmo tempo tem a magia de transmitir, através de um porta-voz, as representações de grupos determinados, em condições históricas, socioeconômicas e culturais específicas" (MINAYO, 2004, p. 109-110).

Deve-se sempre buscar uma atitude crítica em campo, isto é: (1) fazer-se presente como sujeito cognoscente durante a entrevista, pelo exercício da reflexividade; (2) participar objetivamente da entrevista como interlocutor do entrevistado e não como interrogador; (3) tratar o entrevistado como sujeito e não como um depositário de informações; (4) fugir de uma postura de mero coletor ou receptor de dados. Enfim, deve-se evitar uma dupla reificação (do pesquisador e pesquisado), pelo estabelecimento de uma relação sujeito-sujeito, baseada na interlocução. As entrevistas podem assumir aspectos multifacetados para possibilitar uma aproximação do objeto de estudo sob várias perspectivas (DENZIN; LINCOLN, 2000).

Dentre várias possibilidades, este trabalho discorre sobre três tipos de entrevistas que considera adequados às pesquisas críticas em Administração: (i) entrevista com elementos de história de vida; (ii) entrevista com o uso de questão estímulo; (iii) entrevista ficcional. Contudo, ressalta-se que não se trata de pensar as técnicas em si mesmas como críticas, o que seria uma impropriedade haja vista o seu uso em pesquisas as mais diversas, com e sem inspiração crítica; mas utilizá-las sob a lógica de um processo de pesquisa crítico, articuladas às categorias epistemológicas frankfurtianas.

A Figura 1 exemplifica um processo de pesquisa crítico, de orientação frankfurtiana, com conteúdos das diversas 
Figura 1 - Exemplificação do processo epistemológico e metodológico em pesquisas qualitativas críticas, de inspiração frankfurtiana, em Administração
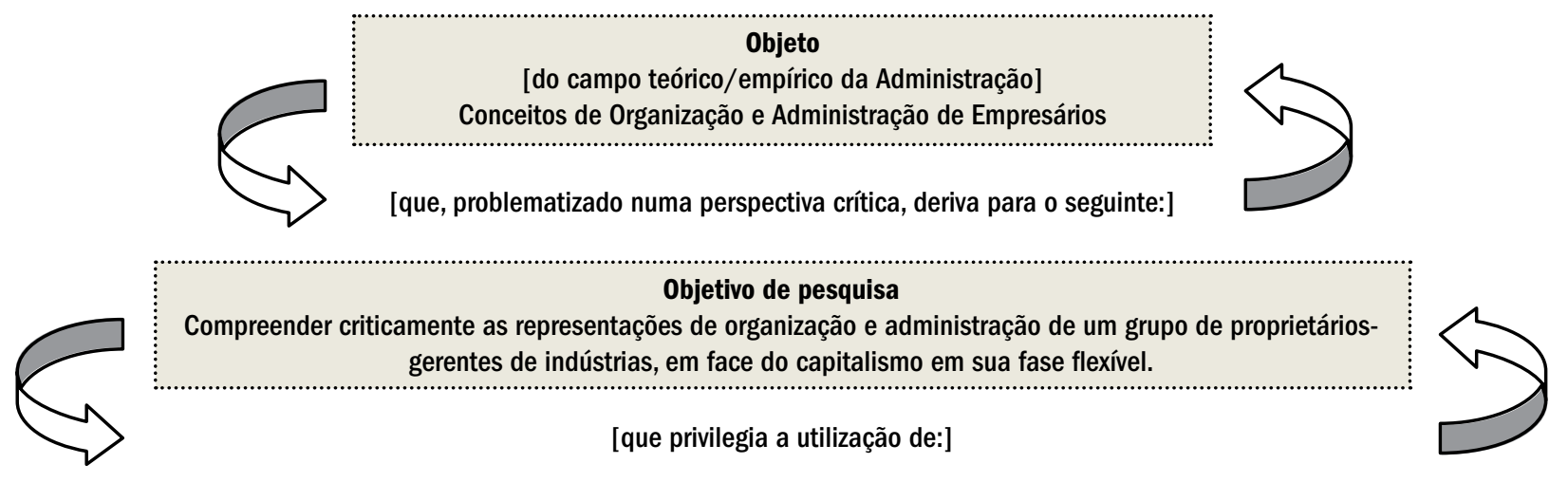

Técnicas qualitativas

Entrevistas com elementos de história de vida e questão estímulo, entrevista ficcional etc.

[que, utilizadas numa perspectiva crítica, podem ser assim exemplificadas:]

Excertos de questões dos instrumentos:

Como o sr. vê a sua empresa? / 0 que o sr. lembra sobre como estava o mundo na época em que iniciou seu negócio? / Que tipo de coisa acontece em um bom dia de trabalho na sua empresa? / Que tipo de coisa acontece em um mau dia de trabalho na sua empresa? / Como o sr. faz para que as coisas andem bem na sua empresa? etc.

["questões" que possibilitam a emergência de conteúdos, tais como:]

Excerto de entrevista:

Ela [empresa] começa, devagarzinho, ela começa bem devagarzinho, aí vai crescendo, crescendo, crescendo, aí vai criando as raízes, os alicerces, aí vai, vai, vai, aí cresce, cria os galhos, cria as folhas, vêm os frutos, mas tem que... não tem o processo de crescimento? Seria como um organismo, como uma planta, pronto, como o próprio ser humano, mas, um ser humano como você, ele não pode comer cinquenta gramas por dia, que você vai adoecer, enfraquecer, e morrer. É a mesma coisa de uma empresa como essa nossa. (sujeito de pesquisa)

[que ensejam:]

Possíveis [e provisórias] sínteses teórico-empíricas críticas:

Narrar a empresa como uma planta ou como o corpo humano é incorrer numa metaforização da organização como um sistema biológico vivo, estando implicadas na metáfora as ideias de adaptação, sobrevivência e reprodução, sob a concepção da organização como organismo. A metáfora sistêmica tem estado presente na literatura organizacional, pelo menos desde os anos 1930. Embora reaparecendo com enfoques diferenciados, a ideia central subjacente é a de uma naturalização sistêmica, que, desde um ponto de vista político, constitui-se também como uma perspectiva contra emancipatória, pois, ao serem comparadas com organismos vivos: 1. organizações são tomadas como um dado da natureza, portanto, a-históricas [história/naturalização] como se 'descoladas' da ação humana interessada; 2 . onde pessoas são tomadas como elementos sistêmicos a serem ajustados [sistema/práxis social]; 3. donde a possibilidade de prática autônoma e consciente deve ser convertida em ações visando à harmonia e ao bom funcionamento sistêmico [alienação/emancipação]. As pessoas narradas como elementos são reduzidas, discursivamente, a seres semelhantes a coisas, exemplificando uma operação discursiva de reificação dos indivíduos. 0 acionamento de pressupostos de outro campo disciplinar (a biologia) parece ser a forma de ocultamento do conteúdo político que envolve a vida nas organizações, e que torna cognoscível a própria metáfora organização-sistema. Ela, organização, é um sistema na medida em que há uma ação interessada que a faz ser pensada, narrada, e vivida como tal. Assim, na metáfora utilizada, o sujeito também assume o discurso teórico do campo da Administração que continua a importar da biologia a forma sistêmica de pensar e interferir no mundo social sem que temas como a tensão histórica entre capital e trabalho, sob a forma capitalista de produção, seja sequer considerada. 
fases da pesquisa. Ela servirá de referência para a explicitação das fases de coleta e análise dos dados, adiante apresentadas.

\section{Entrevista com elementos de história de vida}

O uso da técnica história de vida em pesquisa crítica na área de Administração não se dá em função dos objetivos originalmente vinculados a tal técnica (HAGUETTE, 2001), mas como uma técnica subsidiária, sem se confundir com uma biografia convencional. A história de vida privilegia o uso da memória como recurso de coleta de informações, pois a memória não está ligada ao passado de maneira estanque, mas "empenhada e integrada com o presente, com atitudes, perspectivas e compreensões que mudam continuamente, trabalhando e retrabalhando os dados da experiência em novas reformulações" (HAGUETTE, 2001, p. 93-94). Ademais, e principalmente, a técnica da história de vida possibilita ao narrador tomar a si mesmo como personagem, estando tal técnica "a cavaleiro de duas perspectivas: a do indivíduo [...] e a de sua sociedade com sua organização e seus valores específicos [...] [sendo] técnica que capta o que sucede na encruzilhada da vida individual com o social" (QUEIROZ, 1988, p. 36), aspecto valorizado por estudos críticos que têm as dimensões história e práxis social como norteadoras.

Na pesquisa exemplificada pela Figura 1, os sujeitos eram convidados a narrar suas histórias de vida profissional e a história de suas empresas, no contexto de suas histórias de vida como um todo, visando à emergência das relações diacrônicas, e levando-os a pensar e narrar isso tendo em vista o contexto histórico da sociedade, desde a época de abertura do negócio, passando pelas diversas fases de desenvolvimento da empresa, até o tempo histórico em que a entrevista era realizada.

\section{Entrevistas com uso de questão estímulo}

Segundo Albandes-Moreira (2002), a questão ou elemento estímulo é algo (pergunta, afirmação, proposição) que se apresenta ao entrevistado como um estímulo que - sendo suficientemente amplo, mas necessariamente focal - serve de eixo a uma entrevista. Possibilita ao pesquisador obter o máximo de informação multidisciplinar relevante e necessária à pesquisa crítica sem transformar a entrevista em um interrogatório. Repetindo essa questão de forma transformada e atualizada, ao longo de toda a entrevista, o pesquisador provê condições de exame do tema em termos de práticas e de experiências subjetivas, de afetos e conhecimentos, de teorias e práticas, as mais próximas possível da realidade.
As questões estímulo utilizadas no início de entrevistas em profundidade podem ser desdobradas em questões de apoio cujo fulcro seja as categorias críticas - história, práxis social e emancipação - tomadas como pares dialéticos. As questões de apoio podem ser escolhidas tendo como pressupostos: (a) que o objeto é mais bem abordado quanto menos relação as questões pareçam ter com o tema da pesquisa (ADORNO, 1995a) e, (b) que os sujeitos são mais bem abordados quanto mais as questões estimulem a rememoração do vivido, evocando assim narrativas originárias da vida real, pois, "é [...] nas dobras do cotidiano que a história se realiza" (KRAMER, 2001, p. 174).

Na pesquisa em questão, a pergunta "como o sr. vê a sua empresa?" foi utilizada como questão estímulo que serviu de eixo para que os sujeitos socializassem suas representações. Essa questão foi apoiada por outras (ver Figura 1) no transcorrer da entrevista, na tentativa de operacionalização dos pares dialéticos. Especialmente as escolhas de questões antagônicas, como as que tratavam de um "bom dia de trabalho" ou um "mau dia de trabalho", se mostraram convenientes à possibilidade de emergência de conteúdos ligados à tentativa de modelização sistêmica da realidade e de posturas contraemancipatórias por parte dos sujeitos entrevistados.

\section{Entrevista ficcional}

A entrevista ficcional é uma técnica que objetiva fazer emergir o vivido do sujeito, em sua liberdade criativa, sob a forma de uma narrativa. Inicia com uma exposição, por parte do entrevistador, de uma situação hipotética, realista, a partir da qual o entrevistado pode criar a sua narrativa ficcional. A entrevista suportada por esse tipo de narrativa oferece ao entrevistado maior possibilidade para a seleção do material empírico existencial e experiencial, sendo-lhe dada completa liberdade na criação da narrativa, uma vez que ele não está aprisionado à verdade. O suporte para esse tipo de entrevista é a compreensão de que os discursos ficcionais constituem-se como narrativas no sentido de que são representações dos eventos a que se referem (ALBANDES-MOREIRA, 2002). Essa técnica permite evocar narrativas descoladas dos eventos fáticos, porém plenamente imbricadas nas representações dos sujeitos.

O Quadro 4 apresenta o exemplo de um roteiro de entrevista ficcional utilizado na mesma pesquisa a que se refere a Figura 1.

O roteiro utilizado, baseado na ocorrência de um incidente crítico, permitiu a elaboração de narrativas ficcionais que, em geral, incorriam num discurso naturalizante e sistêmico das situações do cotidiano organizacional, em 
que o poder de mando gerencial era narrado como algo além do sistema, desvelando-se a dimensão política de dominação contida no discurso gerencial.

\section{Compreensão dos resultados}

Adorno (1980) alerta quanto aos cuidados necessários no processo interpretativo dos fenômenos sociais. Aquele que faz a crítica dialética deve evitar tratar o fenômeno e a interpretação de maneira absolutizada, como se houvesse uma invariância fenomenológica com consequente invariância na compreensão, como fazem os positivistas com os seus métodos aplicados ao fato coisificado. Ao contrário, o fenômeno, para o dialético, deve ser encarado como um processo do vir a ser social, e é nessa perspectiva que os sentidos ligados ao fenômeno e sua interpretação devem ser considerados. Para Adorno (1980), a noção de sentido corresponde à essência social que cunha os fenômenos, portanto, situa-se no interstício do individual com o social. Assim, parece estar subjacente ao pensamento adorniano uma lógica de movimento pendular entre o fenômeno isolado e a totalidade da práxis social: "A interpretação dos fatos conduz à totalidade, sem que esta seja, ela própria, um fato. Não há nada socialmente fático que não tenha seu valor específico nesta totalidade" (ADORNO, 1980, p. 217).

Para compreender as informações obtidas em campo, sugere-se aqui a realização de um processo de imersãoimpregnação-compreensão (IIC) das falas dos sujeitos. $\mathrm{Na}$ experiência de pesquisa que embasa este texto, as gravações eram ouvidas por diversas vezes, num processo de recorrências na sequência da gravação, tendo em vista impregnar-se do discurso. Na sequência, o trabalho de transcrição das entrevistas mostra-se relevante para o processo IIC por possibilitar outra forma de contato com as informações. Com a continuação do trabalho de escuta e transcrição, a lógica dos sujeitos entrevistados como que vai se desvelando para o pesquisador, sendo a base para o processo de categorização. As narrativas, então, são interpretadas dentro de um quadro de refe- rência existencial e conceptual, que, por definição, difere daquele do narrador, pelo papel que o pesquisador tem em relação ao discurso, peculiar à sua posição no contexto de pesquisa.

Convergentemente à compreensão de Kramer (2001) de que mais importa como se olha do que aquilo que se vê, em uma pesquisa crítica os discursos dos sujeitos devem ser olhados com a lente crítica. Operacionalmente, assim como em todas as fases anteriores da pesquisa, também nessa fase as categorias críticas (pares dialéticos) guiam o olhar do pesquisador, que deve empreender uma reflexão sobre as narrativas de que dispõe por meio de um constante movimento pendular: (i) entre as partes e o todo; (ii) entre a teoria e a práxis.

Compreendendo como Dellagnelo e Silva (2005, p. 113) que cabe ao "pesquisador questionar aquilo que vê imediatamente, as evidências, as ideias prontas, devendo investir na capacidade de buscar novas interpretações", e num exercício dialético que evita a superficialidade dos fenômenos, buscando sua profundidade, a qual não se mostra à primeira vista; a análise do tipo hermenêutico-dialética (MINAYO, 2004) parece colocar-se como a que mais se aproxima da perspectiva do realismo histórico próprio à TC (LINCOLN; GUBA, 2000).

Segundo Minayo (2004), a análise hermenêuticodialética visa a transcender os aspectos meramente procedimentais associados a técnicas como a análise de conteúdo e análise de discurso, e se propõe como um caminho do pensamento. Nesse percurso intelectual, a técnica hermenêutico-dialética preserva da hermenêutica a possibilidade de interpretação dos sentidos que os sujeitos elaboram em seus discursos, e investe na possibilidade que a dialética fornece de compreender tais discursos em face das contradições e da totalidade da práxis social: "Enquanto a hermenêutica penetra no seu tempo e através da compreensão procura atingir o sentido do texto, a crítica dialética se dirige contra seu tempo. Ela enfatiza a diferença, o contraste, o dissenso e a ruptura

\section{Quadro 4 - Exemplo de instrumento para entrevista ficcional}

Após o jantar, de repente o(a) Sr(a) se percebe rememorando o seu dia de trabalho: o(a) Sr(a) chegou cedo na empresa, antes do pessoal administrativo, pois queria acompanhar a fase final da produção de um grande pedido de um novo cliente. Logo que chega na sua sala, o(a) Sr(a) vê que no aparelho de fax constava um novo documento que deveria ter chegado durante a madrugada ou bem cedo do dia indagando sobre a possibilidade de mudança no pedido desse cliente, contudo, mantendo-se o mesmo prazo de entrega para daqui a dois dias. 0 (a) gerente de produção Ihe interfona informando que uma das máquinas apresentou um problema. O(a) $\operatorname{Sr}($ a) o(a) chama para conversarem sobre 0 assunto... 
de sentido" (MINAYO, 2004, p. 227). Assim, tal técnica se operacionaliza pelo constante movimento pendular entre interioridade e exterioridade, teoria e práxis, dado e mundo, indivíduo e sociedade. A Figura 1 exemplifica o tipo de análise empreendida.

\section{CONSIDERAÇÕES FINAIS}

Considerando o objetivo de socializar compreensões sobre aspectos ontológicos, epistemológicos e metodológicos críticos, de tradição frankfurtiana, em pesquisas na Administração, o texto trouxe contribuições ao apresentar reflexões e exemplificações originárias de uma práxis de pesquisa crítica nessa área. Corrobora o discurso de autores que têm defendido a possibilidade da crítica teóricoempírica na Administração, e o faz fornecendo alguns exemplos sobre "como pensar" e "como fazer" a pesquisa crítica, proposta que tem sido rara no campo. Contudo, os conteúdos ora apresentados não constituem "cartilhas" ou "receitas" dos autores para os leitores, postura que se desvelaria acrítica, posto que modelizante e contraemancipatória. Diferentemente, este texto expõe argumentos e exemplos, pautado na lógica de uma atitude crítica: a do pensamento que pensa a si mesmo numa relação dialética com aquilo que o "real" lhe oferece, entendendo ser esse o desafio para pesquisadores que se propõem críticos.

O texto conclui suas reflexões com uma proposição sintética, argumentando sobre ela: pesquisa crítica constitui-se como permanente diálogo reflexivo com diversos interlocutores.

Primeiro, com a TC enquanto quadro teórico de referência. Nesse sentido, é importante compreender as diversas gerações da Escola de Frankfurt para tomar posição em relação a elas, uma vez que os discursos dessas gerações nem sempre são convergentes, o que implica a necessidade de definição quanto a que perspectiva frankfurtiana orienta a pesquisa.

Segundo, com a teoria dominante no campo que pesquisa. Tal diálogo é imprescindível para que não se caia num denuncismo teoricamente vazio, fruto de uma postura que prefere olhar "de fora" e não "por dentro" do campo que investiga. Assim, é necessário ir à raiz dos conceitos e fenômenos da área em questão, não se furtando ao questionamento radical.

A terceira instância de interlocução é a dos sujeitos de pesquisa. A importância dessa interlocução está no entendimento de que a práxis é o espaço por excelência de síntese entre dois pares dialéticos mutuamente imbricados: teoria-prática e objetividade-subjetividade.
Em uma área como a Administração, que parece não ter abandonado uma postura maniqueísta ao abordar a relação teoria-prática, a leitura frankfurtiana sugere a necessidade de entender o pensar como um agir, a teoria como uma forma de prática, do que igualmente se compreende que toda prática esposa uma concepção teórica, esteja esta academicamente elaborada ou ao nível de uma teoria pessoal. Tratar a pesquisa crítica em sua dimensão teórico-empírica requer compreender que tanto a teoria como a prática se desenrolam na dinâmica objetividade-subjetividade, posto que inscritas na existência historicamente situada dos sujeitos: "Nas opiniões e atitudes subjetivas, manifestam-se também indiretamente objetividades sociais" (ADORNO, 1995a, p. 146). Essa interlocução com os sujeitos de pesquisa pode se estabelecer tanto durante as entrevistas quanto num momento de retorno, após as análises empreendidas sobre seus textos narrativos, investindo na possibilidade de um posicionamento intersubjetivo crítico que resulte num texto negociado, se a situação de pesquisa o permitir.

Finalmente, este texto se abre para o diálogo reflexivo com mais um interlocutor: o leitor. Apresenta-se, portanto, como um convite à interlocução visando à transformação consciente da realidade e dos que sobre ela dialogam.

\section{NOTA DA REDAÇÃo}

Artigo originalmente apresentado no EnEPQ/ANPAD 2009 e submetido à RAE em regime de fast-track.

\section{REFERÊNCIAS}

ADORNO, T. W. A ideia de história natural. 1932. Tradução de Bruno Pucci. Disponível em: http://planeta.clix.pt/adorno/. Acesso em 28.10.2004.

ADORNO, T. W. Experiências científicas nos Estados Unidos. In: ADORNO, T. W. Palavras e sinais: modelos críticos 2. Petrópolis: Vozes, 1995a. p. 137-178.

ADORNO, T. W. Notas marginais sobre teoria e práxis. In: ADORNO, T. W. Palavras e sinais: modelos críticos 2. Petrópolis: Vozes, 1995b. p. 202-231.

ADORNO, T. W. Sobre a lógica das ciências sociais. In: COHN, G. Theodor W. Adorno. São Paulo: Ática, 1986. p. 46-61. (Coleção "Grandes Cientistas Sociais") 
ADORNO, T. W. Introdução à Controvérsia sobre o Positivismo na Sociedade Alemã. In: HORKHEIMER, M; BENJAMIN, W; ADORNO, T. W; HABERMAS, J. Textos escolhidos. São Paulo: Abril Cultural, 1980. p. 117-154. (Coleção "Os Pensadores")

ADORNO, T. W; HORKHEIMER, M. Dialética do esclarecimento: fragmentos filosóficos. 1947. Rio de Janeiro: Jorge Zahar, 1985.

ALBANDES-MOREIRA, L. A. An Exploratory Study on the Nature of the Representations of Organization: Manager and Management within a Group of Teachers of a Business School. Tese de Doutorado na École des Hautes Études Commerciales, Québec, 2002

ASSOUN, P-L. A Escola de Frankfurt. Tradução de Helena Cardoso. São Paulo: Ática, 1991.

BOURDIEU, P. O poder simbólico. 6. ed. Rio de Janeiro: Bertrand Brasil, 2003.

DELLANGELO, E. H. L; SILVA, R. C. Análise de conteúdo e sua aplicação em pesquisa na administração. In: VIEIRA, M. M. F; ZOUAIN, D. M (Orgs) Pesquisa qualitativa em administração: teoria e prática. Rio de Janeiro: FGV, 2005.

DENZIN, N. K; LINCOLN, Y. S. Introduction: the Discipline and Practice of Qualitative Research. In: DENZIN, N. K; LINCOLN, Y. S. (Org) Handbook of Qualitative Research. 2. ed. London: Sage, 2000. p. 1-28.

FARIA, J. H. (Org) Análise crítica das teorias e práticas organizacionais. São Paulo: Atlas, 2007

FARIA, J. H. Economia politica do poder: fundamentos. V. 1. Curitiba: Juruá, 2004.

FARIA, J. H. A Teoria crítica no capitalismo contemporâneo de modernidade tardia. Revista Eletrônica Espaço Acadêmico, ano 3, n. 24, mai. 2003. Disponível em: http://www.espacoacademico.com.br. Acesso em 06.01.2005.

FREITAG, B. A teoria crítica ontem e hoje. 3. ed. São Paulo: Brasiliense, 1986.

GANEM, A. Karl Popper versus Theodor Adorno: lições de um confronto histórico. In: ASSOCIAÇÃO NACIONAL DOS CENTROS DE PÓSGRADUAÇÃO EM ECONOMIA, 37, 2009, Foz do Iguaçu: ANPEC, 2009. Disponível em: http://www.anpec.org.br. Acesso em 17.04.2010.

HAGUETTE, T. M. F. Metodologias qualitativas na sociologia. 8. ed. Petrópolis: Vozes, 2001.
HORKHEIMER, M. Teoria tradicional e teoria crítica. 1937. In: HORKHEIMER, M; BENJAMIN, W; ADORNO, T. W; HABERMAS, J. Textos escolhidos. São Paulo: Abril Cultural, 1980. p. 117-154. (Coleção "Os Pensadores")

HORKHEIMER, M. Materialismo e Metafísica. 1933. In: HORKHEIMER, M. Teoria crítica: uma documentação. Tradução de Hilde Cohn. São Paulo: Perspectiva, p. 31-58, 1990.

HOUAISS, A. Dicionário Eletrônico Houaiss. Rio de Janeiro: Objetiva, 2001. 1 CD-ROM

KRAMER, S. Linguagem e história. In: FRIGOTTO, G; CIAVATTA, M. (Orgs) Teoria e educação no labirinto do capital. Petrópolis: Vozes, 2001.

LINCOLN, Y. S; GUBA, E. G. Paradigmatic controversies, contradictions, and emerging confluences. In: DENZIN, N. K; LINCOLN, Y. S. Handbook of Qualitative Research. 2. ed. London: Sage, 2000.

MATOS, O. C. F. A Escola de Frankfurt: luzes e sombras do Iluminismo. São Paulo: Moderna, 1993.

MINAYO, M. C. S. O desafio do conhecimento: pesquisa qualitativa em saúde. 8. ed. São Paulo: Hucitec/ Rio de Janeiro: Abrasco, 2004.

MUÑOZ, B. Theodor W. Adorno: teoría crítica y cultura de masas. Madrid: Editorial Fundamentos, 2000.

PAUlA, A. P. P. Teoria crítica nas organizações. São Paulo: Thomson Learning, 2008. (Coleção "Debates em Administração")

QUEIROZ, M. I. P. Relatos orais: do "indizível" ao "dizível". In: Von Simson, O. M. Experimentos com histórias de vida. São Paulo: Vértice, 1988.

SLATER, P. Origem e significado da Escola de Frankfurt. Rio de Janeiro: Zahar, 1978

TENÓRIO, F. G. Tem razão a administração? Ensaios de teoria organizacional. 2. ed. Ijuí: Editora Unijuí, 2004.

VAN MAANEN, J. Reclaiming qualitative methods for organizational research: Preface. In: VAN MAANEN, J. (Ed) Qualitative Methodology. London: Sage, 1983. p. 9-18. 